First Peoples Child \& Family Review

An Interdisciplinary Journal Honouring the Voices, Perspectives, and Knowledges of

First Peoples through Research, Critical Analyses, Stories, Standpoints and Media

Reviews

\title{
The Culture of Strengths Makes Them Feel Valued and Competent: Aboriginal Children, Child Welfare, and a School Strengths Intervention
}

\author{
Keith Brownlee, Edward Rawana, Julia MacArthur and Michelle Probizanski
}

Volume 5, Number 1, 2010

URI: https://id.erudit.org/iderudit/1069067ar

DOI: https://doi.org/10.7202/1069067ar

See table of contents

Publisher(s)

First Nations Child and Family Caring Society of Canada

ISSN

1708-489X (print)

2293-6610 (digital)

Explore this journal

Cite this article

Brownlee, K., Rawana, E., MacArthur, J. \& Probizanski, M. (2010). The Culture of Strengths Makes Them Feel Valued and Competent: Aboriginal Children, Child Welfare, and a School Strengths Intervention. First Peoples Child \& Family

Review, 5(1), 106-113. https://doi.org/10.7202/1069067ar

\section{Article abstract}

Schools are an important community partner in providing structural supports and wrap around services for children involved with the child welfare system. In this paper, we discuss the implementation of a culturally sensitive strengths-based intervention approach within an elementary school and its value to Aboriginal children. This article discusses the theoretical foundation of the strengths intervention approach and provides a description of a strength assessment tool as well as the implementation of the intervention with specific relevance to Aboriginal students involved with the child welfare system. Two case studies are presented, which illustrate the value of the strengths approach for individual students.
Copyright (C) Keith Brownlee, Edward Rawana, Julia MacArthur, Michelle Probizanski, 2010
This document is protected by copyright law. Use of the services of Erudit (including reproduction) is subject to its terms and conditions, which can be viewed online.

https://apropos.erudit.org/en/users/policy-on-use/ 


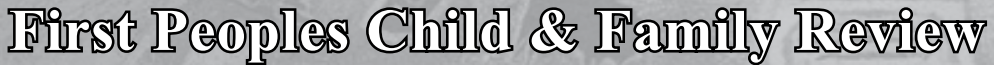

An Interdisciplinary Journal Honoring the Voices, Perspectives and Knowledges of First Peoples through Research, Critical Analyses, Stories, Standpoints and Media Reviews

Volume 4, Number 2, 2009, pp. 106-113

\section{The Culture of Strengths Makes Them Valued and Competent: Aboriginal Children, Child Welfare, and a School Strengths Intervention}

\author{
Keith Brownlee ${ }^{a}$, Edward Rawana ${ }^{\mathrm{b}}$, Julia MacArthur ${ }^{\mathrm{c}}$ and Michelle Probizanski ${ }^{\mathrm{d}}$
}

a Ph.D., a Professor, School of Social Work, Lakehead University, Thunder Bay, Ontario, Canada.

${ }^{\mathrm{b}}$ Director of Research for the Centre of Excellence for Children and Adolescents with Special Needs, and Assistant Professor, Department of Psychology, Lakehead University, Thunder Bay, Ontario, Canada.

c Graduate Student, School of Social Work, Lakehead University, Thunder Bay, Ontario, Canada.

dPrincipal, McKellar Park Public School, Lakehead Public Schools, Thunder Bay, Ontario, Canada.

\section{Introduction}

When families become involved with child welfare services, it is often due to being in crisis situations (CrossonTower, 2008), either temporary or recurrent. These experiences can be disruptive and stressful for children, who frequently face major uncertainty regarding their families and their future care, even when their families are receiving the best possible interventions. This, in turn, can negatively impact children throughout all areas of their lives. This paper examines a new approach that has been introduced at McKellar Park Central School, which is an inner city elementary School where Aboriginal children involved in child welfare services are benefiting from a school/community-based strengths intervention approach, which assesses, promotes, and utilizes

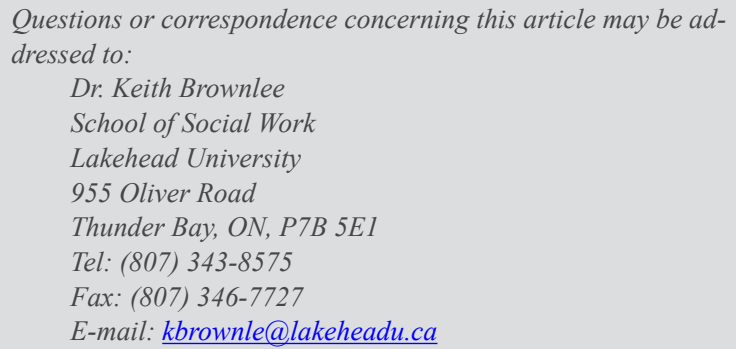

\begin{abstract}
Schools are an important community partner in providing structural supports and wrap around services for children involved with the child welfare system. In this paper, we discuss the implementation of a culturally sensitive strengths-based intervention approach within an elementary school and its value to Aboriginal children. This article discusses the theoretical foundation of the strengths intervention approach and provides a description of a strength assessment tool as well as the implementation of the intervention with specific relevance to Aboriginal students involved with the child welfare system. Two case studies are presented, which illustrate the value of the strengths approach for individual students.
\end{abstract}

a full spectrum of strengths for each individual (Rawana \& Brownlee, 2009). The intervention makes it possible for the school to play an important role as a community partner in providing the kind of relationships and structural supports that are vital for helping children to foster resilience.

Aboriginal children who are involved with child welfare services face all the same issues as non-Aboriginal children. These issues include significant transitions, potential trauma, and high mobility. But for Aboriginal children there are added considerations such as an historical legacy of children being taken from their families and communities (Chansonneuve, 2005; Lafrance \& Bastien, 2007), a much higher percentage of children in care (Baskin, 2007), on-going considerations regarding culturally competent foster placements (Blackstock, 2005; Sinclair, 2007), as well as endemic structurallyentrenched poverty affecting Aboriginal communities across Canada (Kendall, 2001). The School strength intervention approach described in this paper uses unique assessment tools, providing children with an increased awareness of their personal strengths (Rawana \& Brownlee, 2009). Not only can the child draw upon their personal strengths from one area of their life to have a positive influence in another area, but they 
can also use their strengths in whatever paths their lives take. Therefore, even the children who access the intervention for limited amounts of time get the benefit of increased selfawareness about their strengths, as well as the experience of any practical application of their strengths that they are able to access while at the school.

This article first discusses issues facing Aboriginal children in the child welfare system at the school, followed by a review of the theoretical foundation of the strengths approach, a description of the strength assessment tools, and an overview of the implementation of the approach with its specific relevance for Aboriginal students involved with the child welfare system. Finally, two case studies are presented, which illustrate the value of the strengths approach for individual students and demonstrate the effectiveness of providing wrap-around services to students in an urban, inner-city elementary school.

\section{Aboriginal Child Welfare Context}

Children who are involved with child welfare are some of the most vulnerable people in our society. However, as is the case for all children, it is evident that children involved with the child welfare system are not without strengths, gained both from surmounting adversity as well as from the presence of everyday positive life experiences (Kirven, 2000). CrossonTower (2008) outlines the four reasons for the involvement of child welfare services with families in crisis: "(1) failure to complete basic tasks, (2) failure to adapt to changes brought on by developmental tasks, (3) failure to deal with crises, and (4) failure to deal with societal pressures" (p. 43). The child welfare service itself often becomes one of the crises with which parents have to cope. It is easy to see how under such conditions the families themselves may fail to notice or appreciate their own strengths.

Children involved with the child welfare system have experienced disruptions in their home life, often from emotionally unsettling events. Frequently, changes in primary caregivers, either entering foster care, returning to immediate or extended family, or moving between foster caregivers, affects children's school performance. Kirven (2000) argues that children's identities often form through the input of school, peers, extra-curricular activities, neighbourhood and community; which interestingly are some of the domains that are assessed in the assessment of child strengths that are discussed later in this paper. When a child welfare situation impacts the lives of Aboriginal children, one must consider the potential effects of being removed not only from immediate family, but also potentially from a tightly knit extended family. Further, this can also change or strain relationships with family and others who are living in First Nation communities and contribute to a sense of isolation often experienced by Aboriginal people who have recently moved to urban centres (Graham \& Peters, 2002). Feelings of loss of access to culture or spirituality, if the placement is not culturally appropriate in some way, can also intensify the child's sense of isolation. As Justice René Dussault (2007) recounts: "Children judged to be vulnerable were routinely made wards of provincial agencies and placed in non-Aboriginal foster homes. External agencies have been slow to understand the profound cultural differences and adjust their approaches accordingly" (p.9). The most common issues facing the Aboriginal students of McKellar Park School involved with child welfare services are high levels of transition in school life, home life, and between communities, lack of access to resources, isolation due to new urban settings, and high levels of mobility (Graham \& Peters, 2002). The strengths intervention approach includes multiple components of that can positively influence the experiences of these children.

\section{Theoretical Foundation of Strengths at McKellar Park Central School}

Saleebey (2006) describes the strengths perspective as mobilizing clients' talents, knowledge, capacities, and resources "in the service of achieving their goals and visions" so the client can "have a better quality of life on their terms" (p. 1). This conception of strengths includes several key concepts. First, is the idea that everyone has strengths and that clients can draw upon the different areas of strengths in their lives to achieve their personal goals. Second, an individual can utilize these strengths to achieve a better quality of life, when the strengths are consciously perceived as valuable and transferable. Third, the conceptualization of strengths as the knowledge, capacities and resources that clients already possess to their benefit is particularly important for clients who may not conform to the norms of the dominant culture. It allows a conceptualization of personal strengths that is unique to an individual's worldview, and the worldview of one's family, community, and culture. Although the strengths perspective is used throughout the field of social work, and has generally been shown to be effective in practice (Saleebey, 2006; Tedeschi \& Kilmer, 2005), the translation from perspective to model has been relatively vague when applied to families and children and has tended to rely heavily on a resilience-based application.

Rawana and Brownlee (2009) support the need to clarify the operationalization of the strengths perspective in its application with families and children and have offered a model of their own that easily extends to a school environment. In their assessment and intervention model, they identify strengths within all domains of a child's everyday functioning, 
not just in relation to an experience of adversity as would be the case with a resilience-based model. This is particularly salient to children and families involved with the child welfare system where the sense of adverse life circumstances can sometimes seem overwhelming. For instance, in a resilience-based conceptualization of strengths an Aboriginal child who has been taken into care due to domestic violence within his family would be encouraged to draw on the ways he coped with this situation in the past, such as seeking help with extended family or bonding with siblings (Glicken, 2004). However, using the model described by Rawana and Brownlee (2009), which includes an appreciation of the child's strengths that are not necessarily based on adversity, the child may be found to have a profound connection to his culture and positive involvement with his hockey team. The child could draw upon both of these areas of strength for dealing with the experience of being in care as well as dealing with the trauma of domestic violence.

The Rawana and Brownlee strengths model highlights the capacity of children to maximize their potential, to improve their lives and to deal with difficult events. The inclusion of a Strengths Assessment Inventory (SAI) enables a wide range of strengths to be identified that are valued both by the individual and society, including cultural and spiritual sources of strengths (Rawana \& Brownlee, 2009). Given the importance of culturally appropriate practice within social work (Morrissette, McKenzie \& Morrissette, 1993), including the incorporation of spirituality (Zapf, 2005), it is essential to ensure that clients' needs are being met culturally. This aspect of service can pose challenges, as not only do all individuals have different perceptions of and identifications with their own cultures, but also social workers are often serving clients whose culture differs significantly from their own. However, since the Rawana and Brownlee model evaluates strengths in such a broad spectrum of the client's life, the strengths that may potentially be drawn from cultural practices can be assessed and included in any intervention with the child and family.

\section{Strengths Assessment}

The value of a comprehensive assessment of strengths, usually in the form of an interview, has been widely recognized by social workers as an important component of a strengthbased approach to clinical work (Cowger, 1994; De Jong \& Miller, 1995; Glicken, 2004). The strength assessment protocol developed and described by Rawana and Brownlee (2009) emphasizes the value of a structured strength-based questionnaire, which involves multi-source and multi-site procedures. A multi-source assessment could involve the child, parent and service providers such as social workers and teachers. The multi-sites are generally home and school. An assessment instrument is preferred because of the ease with which the information can be collected from a number of key people. Thus, the child can complete a self-report whereas parents, teachers, clinicians and other community leaders can use a rating scale that is equivalent to the self-report but designed for adults who are familiar with the child. By using this instrument, a description of observed strengths can be readily gathered about the child.

This strategy of multi-source, multi-site assessment lends itself to the organization of strengths information according to naturally occurring structures in the environment which Rawana and Brownlee label domains of functioning. A relatively simple way to describe the domains is to separate them into two major categories: Contextual Domains, which refer to the context in which the child interacts with others, and Personal Developmental Domains, which refer to the more individualized functioning of the child. Both the contextual and personal developmental domains reflect day-to-day functioning throughout the lifespan of the child. The contextual domains include Peers, Family/Home, School, Employment, and Community, while the personal development domains include Personality, Personal and Physical Care and Leisure or Recreation, Spiritual and Cultural Development and Current and Future Goals. Some domains include aspects of the child's life that become more pertinent as the child matures, such as employment, community involvement or spiritual and cultural development.

By presenting the information on identified strengths according to the domains of functioning, the school-based intervention offers the child and family a framework that enables them to recognize quickly and easily which areas of the child's life are going well. It also allows the child and family to appreciate if the child's strengths tend to be concentrated in specific areas rather than over a broader range of domains, or even if the child is possibly struggling in some areas. This process usually includes new information as well as characteristics of the child that are widely appreciated and fuses it into a framework that makes it possible to have conversations about a variety of strengths as well as conversations about why the child may have invested in some strengths rather than in others or conversations about how the child might be able to employ the strengths he or she has in one domain to improve functioning in another domain. Since the assessment seeks to gather information on actual strengths and can include an evaluation of the child's strengths by others, there is a greater chance that the strengths are an accurate reflection of the child and allow realistic expectations to be developed. 


\section{Implementation of a School Based Strengths Intervention Approach}

McKellar Park Central School is an inner-city school located in a relatively lower socio-economic area of Thunder Bay, Ontario. The school has a population of 265 students with approximately $50 \%$ of the students self-identifying as First Nations. For approximately the last year and a half McKellar Park Central School has been involved in the implementation of a bullying project based on a strengths perspective and the case studies given below are based on this experience. At McKellar Park Central School a comprehensive strengths evaluation forms the foundation of the strengths intervention approach. The built-in cultural appropriateness of the approach suits the diversity of the student body. McKellar Park Central School uses the assessment of student strengths to promote a positive school environment, by using the students' personal assets to deal with some of the problems that they are experiencing in their lives. The intervention has many components, all of which incorporate the students' strengths, and all of which are dynamic, in that they are able to evolve and adapt as the intervention continues. By initially assessing the students' strengths, the students become conscious of their personal potential to contribute not only to the school community, but also throughout all aspects of their lives. These strengths are portable and transferable, so that student may explore how they can use strengths that they have in one domain to respond to challenges in a different domain. The assessment stage is the first step for involving students to begin to reflect on their potential. Many other components of the intervention provide an opportunity for the students to actively use the strengths that are assessed, to contribute to, participate in, and become members of the school community.

Benard (2006) highlights the ways in which people are able to develop healthily and learn successfully: "having the opportunities to be heard, to voice one's opinion, to make choices, to have responsibilities, to engage in active problemsolving, to express one's imagination, to work with and help others, and to give one's gift back to the community" ( $p$. 203). The strengths intervention approach at McKellar Park provides opportunities for students to do all of these things, which according to Benard will result in the development of students' social competence, problem-solving skills, positive use of self, and their sense of purpose and future. Essentially, various components of the strengths intervention demonstrate to students not only that they have strengths, and that they have the potential to use them, but also allow students to actively test their strengths, through positive participation in the school community. The participation is not limited to the formal components of the intervention either, but is generally applicable to all aspects of school life through the development of a 'culture of strengths'

The school has had a very positive response to the strengths initiatives that it has undertaken, and has succeeded in creating a welcoming culture of respect, caring and competence. This has been particularly successful with Aboriginal students, who have responded exceptionally well to the strengths approach. For children who are already familiar with the strengths perspective through involvement with social work professionals, such as children encounter in child welfare services, this kind of wrap-around approach serves to reinforce the notions that they have already encountered. The true measure of success for an intervention is whether it is able to positively affect a client's life outside of the therapeutic relationship. Thus, the involvement of the school system in offering a strength-based intervention is important in helping to consolidate a wider application of any therapeutic work. The next section discusses the individual components of the strengths intervention approach at McKellar Park Central School and how they work towards helping Aboriginal children, including those who may be involved with child welfare services, develop wider social competence, problemsolving skills, positive use of self, and their sense of purpose and future. In addition, the discussion and the two cases illustrations that follow focus on how the intervention approach supports the child through the difficulties that they often experience while they are involved with the child welfare system.

\section{Components of the McKellar Park Strengths Intervention Approach}

Common issues encountered by Aboriginal children involved with the child welfare system are high levels of transition in home and school life and even between communities. These transitions are often paired with isolation emerging from the high levels of mobility, especially if the family is entering a new community, as well as changes in the family's access to resources. Many elements of the strengths intervention are helpful with these issues.

The first component of the intervention approach is the completion of a personal strengths assessment using the SAI as described above by both the child and sometimes by the teaching staff and parents or caregivers. This information was shared with significant stakeholders, particularly to ensure all the key helpers can facilitate the expression of these strengths. The next component in which a student may participate is the "Good Start Centre." This consists of giving a fair start to students who join the school during the year. During two half-day sessions, the students and their families are set up for success emotionally, socially, and academically within 
the school. The school's administrator, or Special Education teacher, will spend this time with the families ensuring that both the students and caregivers feel comfortable in the school and community. This may include, but is not limited to, informing the family where they can access community resources, performing academic testing on the students, and involving the students in a buddy program. A strengths inventory is completed with the parents and students, and this information is used to successfully integrate the students into the school community. For example, if someone is good at sports, this becomes an important part of his or her school experience. This helps to make the student feel comfortable thus preventing the anxiety that can sometimes lead to negative behaviours. For Aboriginal children who are in care, changes in foster placements may occur or the children may return to their biological parents or extended families. Although it is often the goal of child welfare agencies to prevent school changes midway through the year, it is sometimes unavoidable. This component of the strengths intervention helps to ease the transition into the new school at a time when children are facing multiple transitions in their lives.

Another strategy used is cool down and prevention time. Students who are experiencing difficulty on a particular day will spend time with a caring adult in the school who is aware of their strengths. During this time, they discuss how the student could engage in behaviours that are more positive by using some of the student's personal strengths, and thus avoid the situation that put him or her in cool down in the first place. This intervention empowers students to make better choices and to have a hand in creating a more positive school culture. For students who are experiencing turmoil at home and within their families, this approach allows them to reflect on the challenges they are facing, including the challenge of maintaining positive behaviours at school when there are personal issues that can be distracting to them, or causing stress while they are at school. During this time, which the student spends in self-reflection with the adult, they both make an effort to explore and expand on the assessed strengths of the student and to plan strategies that could help in dealing with these challenges using the strengths that the student has identified.

A fourth component is the use of alternatives to suspension practices. The administrators use alternatives to spending time at home when something has occurred that may have warranted a short suspension. This is a step in progressive discipline, where the child works on social skills, may partake in restorative practice, or a talking/healing circle. It is consistent with the above-mentioned approaches, in which the student's strengths are being utilized to engage in a restorative conversation. Time is spent working through a resolution of the issue that benefits all involved. This is effective if the child is beginning to engage in negative behaviours, which potentially could lead to the breakdown of foster placements. In addition to being a progressive method of discipline within the school, it potentially can help to maintain the foster placement for longer, because the child will continue to attend school instead of being in the constant care of the foster parents, and will be engaged in on-going reflection on personal strengths and alternatives to negative behaviours.

The Ambassador's Club is another important component that builds on the child's strengths, both in terms of philosophy and implementation. It is comprised of students, selected because the staff feel that they could benefit from further opportunities to engage in positive behaviour, to "give one's gift back to the community" (Benard, 2006, p.203). The intervention approach employs children who do not tend to excel in the traditional areas on which students are assessed in a school setting, such as on academics, or classroom behaviour. These students' strengths have been evaluated and used to make them aware that positive power situations exist in the school to replace negative behaviours that are being perpetrated or experienced by the students. Students are experiencing the success of helping to be a part of the solution, rather than expediting the problem, by being helpful to each other, as well as to the school community. The students spend a lunch hour every two weeks with the administrators working on social skills, problem solving, discussing how to improve school situations to make these situations more inviting to other students, as well as, organizing activities for the school. The students also run assemblies and give tours to new students. For children who are experiencing a profound lack of control over their lives, such as is often the case for children in the child welfare system, the sense of taking on responsibilities, and being rewarded for good behaviour (which can also be a problematic aspect of child welfare if the child perceives his or her behaviour as being the cause of entering into care) can increase selfesteem, self-efficacy, and a sense of positive accomplishment. These children are garnering attention for their positive actions, reinforcing the strengths that have been previously assessed.

The final formal component of the strengths intervention approach is the participation of the New Experiences Program, which is provided by a children's mental health agency, namely, the Children's Centre Thunder Bay. The New Experiences Program staff provide student and parent workshops and consultations, and address specific issues that come up in students' experiences. For example, some workshops have addressed grief, trauma, bullying, Seven Grandfather teachings, role models, the development of goals and dreams and appropriate coping skills. This occurs once a week in 
the school, and is a way to involve caregivers in the dialogue that is occurring within the school about students' strengths. Biological parents, foster parents, and extended family are all welcomed into the school to participate, increasing the sense of community within school. This is a way to facilitate the transfer of strengths between different aspects of children's lives.

Once the strengths intervention approach began at McKellar Park Central School, the teachers at the school wanted to utilize their students' strengths more actively in the classroom. The teachers actively and dynamically introduced the strengths approach into the classroom, based on the strengths assessments completed by all the students. Most of the classrooms in the school now have a 'strengths wall,' on which the students' key strengths are listed. These strengths walls have the benefit of being easily changeable, so that when students are able to utilize previously untapped strengths, the wall can be changed to reflect it. This occurred as an adjunct to the initial conceptualization of the strengths intervention approach, but quickly became a focal point of students and staff. No student was left without a visual representation of what they brought as individuals to the school community. Strengths language was quickly absorbed into students' and teachers' vocabularies, and an entire strengths culture began to take shape within the school.

\section{Case Studies}

\section{Case One}

John, a thirteen-year-old male, at McKellar Park Central School has been repeatedly taken into the care of the local Aboriginal child welfare agency, and returned to his biological mother's care throughout his life. In his mother's home, John was a witness to domestic violence, and experienced violence himself. He has always lived in poverty. John acted out throughout his elementary school career, usually with aggression and violence, which often resulted in being suspended from school. Although the teachers at school recognized that John's behaviour was a carry-over from his home life, they still were challenges to deal with his "lack of obedience to adult authority."

After participating in the school's strength intervention approach, John has undergone a number of positive changes which have been sustained for at least a year and would appear to be stable. He is described as a leader, an athlete, and as being very helpful in the school. He is discovering his strengths in the school, and in the relationships he is forming with others within the school. John's negative behaviours subsided, and he began to "understand who he [is] as a person, and what his strengths [are] in the school." After the strengths intervention started, John made the decision to live with his grandmother, rather than continue living with his mother. His grandmother's home is a stable, supportive environment. He has also found the capacity to stand up for himself to his mother, and to defend the decisions that he makes based on what is best for himself. He has had to take these actions in the school setting occasionally, and has been able to draw on the supportive, strength-based relationships that he has developed with the adults at the school. He has become much more self-reflective, and is able to see patterns in his behaviour, and recognize why they are occurring. For example, looking at his own data documenting the behaviour incidents that he has had throughout his school career, John recognized that negative behaviours often peaked in January. John recognized that Christmas was not a good time in his family, and was able to see the connection between his anger and acting out when he returned to school each January.

John is a member of the Ambassador's Club, and has willingly attended every New Experiences workshop. Both his mother and his grandmother also participated in the New Experience workshops. According to the principal of the school, running interventions for both parents and children not only provides valuable education to both parties, but also allows children to witness their parents committing to their own and the child's well-being, and modelling participation in the community.

John has become a fully participating member of the school community since the strengths intervention approach has begun. He has built positive relationships with the adults at the school. He knows that they want him to succeed, and he is motivated to follow through to achieve success, and to live up to the reputation that he has created for himself. In addition, the negative behaviours that were being carried from home life into John's school life have reversed; he is now bringing the positive strengths he is discovering at school into his home life, to make decisions and take actions that are to his benefit.

\section{Case Two}

Sarah, a twelve-year-old female at McKellar Park School, currently lives with her biological family, she has been taken into foster care at various points throughout her life, and it remains an on-going issue within the family. Sarah's home is not stable, and there are on-going struggles with the living conditions, due to poverty. Both the adults at the school and Sarah herself worry about her well-being. Sarah engaged in aggressive, violent behaviours, including relational bullying of other girls. She also used drugs and frequently came to school under the influence of drugs, before starting with the strengths intervention approach. Sarah faced suspension on several occasions, and also was frequently absent from school. 
Since the strengths intervention approach was implemented at the school, the principal has not had a single incident when Sarah has had to go to the principal's office. It has been over a year since the principal has had to deal with Sarah's negative behaviours. Before the strengths intervention formally began, Sarah was given alternatives to suspension for her behaviours, an action that has carried over into the strengths intervention approach. She responded very well to the adult interventions that accompany the alternatives to suspension, and Sarah participated in positive discussions, and has learned coping and life skills, instead of spending the time at home. She has, like John, participated in all of the New Experiences workshops, and her father has attended each of them as well. Again, the opportunity for children to see their parents demonstrating their care and concern for them has more implications in home life, and the carry over of the strengthsoriented culture and language from school to home by both parent and child cannot be understated. Sarah also participates in the girls' drumming group that takes place each week, and has become very focused on athletics.

In Sarah's case, she has definitely benefited from the culture of strengths that has permeated the school community. She has been "pumped up" by adults in school, who recognize her positive behavioural changes. She no longer uses violence or bullying, and the principal believes that no one in the school feels victimized by Sarah. Neither does she come to school under the influence of drugs, nor does she skip class any more. The principal said, "She's a non-issue. She's one of my stars." This highlights the fact that in addition to Sarah's behaviours becoming a 'non-issue', she is now being recognized for her positive actions and for the changes that have occurred in her behaviours. From the strengths surveys, she has identified athletics as an area of strengths for her. When asked about the turnaround in her behaviour, she identified participation in sports as one of the motivations to come to school. Her attendance is no longer an issue and the goal-oriented thinking and identification of her strengths helps Sarah maintain her improved attendance. Because the school itself has a culture of strengths, it has become a place where Sarah knows that people care about her, and where the structure, setting, peacefulness, and the relationships that she has built all support and enhance her own strengths.

\section{Conclusion}

The strengths intervention approach implemented by the school has affected all students in the school, but has garnered remarkable results with the Aboriginal population. The specific outcomes noted for the children and families involved with child welfare have been of particular interest, as this population faces increased risks and challenges both within the school setting and in home life. The principal of the school stated that, "It's really the culture of strengths rather than any component of the approach. It's the culture of strengths that make [the children] feel like this is a home environment, that [they're] respected." The interventions undertaken in the school's strengths intervention approach give these children the unparalleled opportunity to name and identify their strengths, and have these strengths recognized by caring adults, as well as for the children to discover the potential that already exists for their development. Most importantly perhaps, it gives the child a safe, nurturing environment to experience the positive results of expressing and exercising their personal strengths. The culture of strengths within the school becomes a springboard for these children to realize their potential in all areas of their lives. It also contributes to the structural conditions, relationships and access to social supports that are essential if children are to develop the individual capacities to acquire resilience (Boyden \& Mann, 2005; Ungar, 2004) that will enhance their chances of successfully navigating their way through the child welfare system.

Since the identified strengths discussed above are transferrable between home, school and the community, these children are able to see that their identity is closely intertwined with their strengths. This development, therefore, may help them to navigate successfully through child welfare situations that they either have encountered in the past or will encounter in the future.

Finally, the program described in this paper has built-in quantitative, qualitative and case study components to the design in order to explore longitudinally the changes that have occurred in the school from the inception of the program to its completion which is intended to occur in December in 2009. While the evaluation of this program will be completed, the successes to date have encouraged the administrators and staff at McKellar Park Central School to continue with the program as part of regular practice.

\section{References}

Baskin, C. (2007). Aboriginal youth talk about the structural determinants as the causes of their homelessness. First Peoples Child \& Family Review, 3(3), 31-42. Available online at http://www.fncaringsociety.com/pubs/ vol3num3/Baskin_31.pdf.

Benard, B. (2006) Using strengths-based practice to tap the resilience of families. In Saleebey, D. (Ed.), The strengths perspective in social work practice (2nd ed.), pp. 1-23. Toronto: Pearson Education.

Blackstock, C. (2005). Community-based child welfare for Aboriginal children: Support resilience through structural change. Social Policy Journal of New Zealand, 24, 12-33. 
First Peoples Child \& Family Review, Volume 5, Number 1, 2010

Boyden, J., \& Mann, G. (2005). Children's risk, resilience and coping in extreme situations. In Ungar, M. (Ed.), Handbook for working with children and youth: Pathways to resilience across cultures and contexts, pp. 3-26. Thousand Oaks, CA: Sage

Chansonneuve, D. (2005). Reclaiming connections: Residential school trauma among Aboriginal people. Ottawa: Aboriginal Healing Foundation. Retrieved March 7, 2009 from http://www.ahf.ca/pages/ download $/ 28 \quad 101$.

Cowger, C. D. (1994). Assessing client strengths: Clinical assessment for client empowerment. Social Work, 39, 262-268.

Crosson-Tower, C. (2008). Understanding child abuse and neglect (7th Ed.). Toronto: Allyn \& Bacon.

De Jong, P. \& Miller, S. D. (1995). How to interview for client strengths. Social Work, 40, 729-736.

Dussault, R. (2007). Indigenous peoples and child welfare: The path to reconciliation. First Peoples Child \& Family Review, 3(3), 8-11. Available online at http://www.fncaringsociety.com/pubs/vol3num3/ Dussault_pp8.pdf.

Glicken, M. D. (2004). Using the strengths perspective in social work practice. New York: Pearson.

Graham, K. A. H., \& Peters, E. (2002). Aboriginal communities and urban sustainability. Ottawa, ON: Canadian Policy Research Networks.

Kendall, J. (2001). Circles of disadvantage: Aboriginal poverty and underdevelopment in Canada. The American Review of Canadian Studies, 31(1-2), 43-59.

Kirven, J. (2000). Building on strengths of minority adolescents in foster care: A narrative-holistic approach. Child \& Youth Care Forum, 29(4), 247-263.

Lafrance, J. \& Bastien, B. (2007). Here be dragons! Reconciling Indigenous and Western knowledge to improve Aboriginal child welfare. First Peoples Child \& Family Review, 3(1), 105-126. Available online at http:// www.fncaringsociety.com/pubs/vol3num1/Lafrance_Bastien_pp105. pdf.

Morrissette, V., McKenzie, B., \& Morrissette, L. (1993). Towards an aboriginal model of social work practice. Canadian Social Work Review, 10(1), 91-107.

Rawana, E. \& Brownlee, K. (2009). Making the possible probable: A strengthbased assessment and intervention framework for clinical work with parents, children and adolescents. Families in Society, 90(3)

Saleebey, D. (2006). Power in the people. In Saleebey, D. (Ed.), The strengths perspective in social work practice (2nd Ed.) (pp. 1-23). Toronto: Pearson Education.

Sinclair, R. (2007). Identity lost and found: Lessons from the sixties scoop. First Peoples Child \& Family Review, 3(1), 65-82. Available online at http://www.fncaringsociety.com/pubs/vol3num1/Sinclair_pp65.pdf.

Tedeschi, R. G. \& Kilmer, R. P. (2005). Assessing strengths, resilience and growth to guide clinical interventions. Professional Psychology: Research and Practice, 36, 230-237.

Ungar, M. (2004). Nurturing hidden resilience in troubled youth. Toronto: University of Toronto Press

Zapf, M.K. (2005). The spiritual dimension of person and environment: Perspectives from social work and traditional knowledge. International Social Work, 48(5), 633-642. 